\title{
OPTIMIZATION OF CONSTRUCTION PARAMETERS OF A FLOOR CONVECTOR
}

The paper deals with optimization of construction parameters of a floor convector with natural convection. Intensification of heat transfer from the floor convector with an objective to achieve the highest possible thermal performance of the floor convector was performed by CFD method and criterion equations at boundary conditions, like ambient temperature $20^{\circ} \mathrm{C}$ and the temperature of the heating medium $75 / 65^{\circ} \mathrm{C}$ in thermostatic chamber.

Keywords: Floor convector with natural convection, rib, spacing.

\section{Introduction}

Floor convectors are heating bodies used in the places where it is necessary to install heaters with a low construction height or where these heaters are to be mounted into the construction of the floor. To achieve the highest possible thermal performances of floor convectors with natural convection with the maximum construction height up to $100 \mathrm{~mm}$ some experimental measurements to optimize construction parameters of the floor convector were made in a thermostatic chamber.

\section{Construction of a floor convector}

The floor convector consists of the following elements: grille (wooden or metal), trim frame and housing. The most important

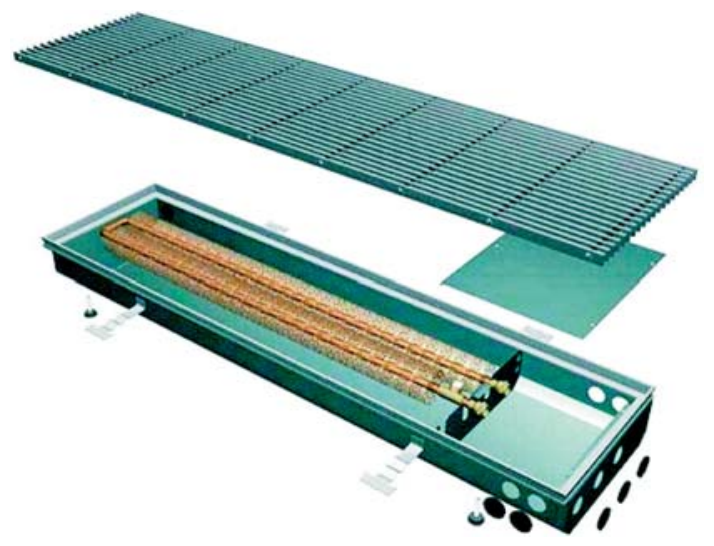

Fig. 1 Part of a floor convector part is the exchanger placed in the housing. The exchanger is composed of a copper tube with molded aluminum fins to achieve a higher thermal performance. Exchangers usually have matrices with an internal diameter $\mathrm{G} 1 / 2$ " on the one side, and welded air vent on the other side. All this parts we can see at Fig. 1.

\section{Heat transfer and floor convectors}

The process of heat transfer by the floor convector with natural convection from the heat transfer medium into the ambient air can be divided into (Fig. 2):

1. heat transfer from hot water to the tube wall,

2. heat transfer through the tube wall and heat transfer in the rib (conduction), and

3. heat transfer from the outer tube wall and heat transfer from the rib wall to the air by free convection.

The problem of heat transfer from the floor convector with natural convection can be solved analyzing the basic equations of conservation of (mater, energy, and impulse) and equations of state describing a thermodynamic situation of flowing gas, on the basis of loss calculations for flow, equations of heat transfer and relations for properties of substances. The quantification of thermal flows in real equipment is, owing to the complicated flow fields, most frequently carried out by means of criterion equations.

To simplify and speed up optimization processes, the model of heat transfer from the floor convector with natural convection was constructed on the basis of criterion equations. First of all, the optimal rib spacing at different ribbing heights was looked for to optimize floor convectors with a construction height up to $100 \mathrm{~mm}$. Consequently, the rib thickness enabling the highest performance

\footnotetext{
* Andrej Kapjor, Milan Malcho, Jozef Jandacka, Jozef Huzvar, Tomas Gressak

Department of Energy Technology, Faculty of Mechanical Engineering, University of Zilina, Slovakia, E-mail: andrej.kapjor@fstroj.uniza.sk
} 


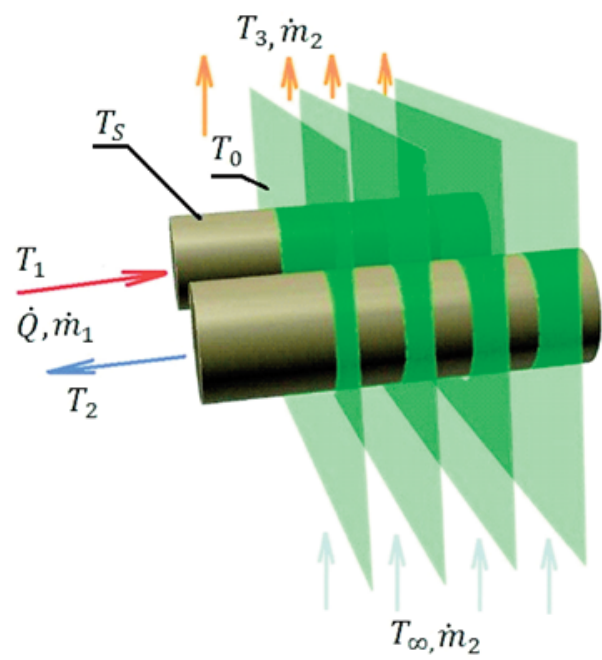

Fig. 2 Heat transfer by a floor convector from the heat transfer medium to the ambient air

of the floor convector at various rib heights was looked for. As the above mentioned process of heat transfer from the floor convector to the ambient air takes place in the housing of the convector, we also investigated the influence of the housing itself on the floor convector performance.

The optimization itself was performed on a sample of the floor convector having a length of the ribbed surface $740 \mathrm{~mm}$ because experimental measurements were also made on floor convectors having the same length, which enabled us to compare and verify the calculation model with real measurements of floor convectors in a thermostatic chamber. The calculation model of the floor convector was set up on the basis of criterion equations of probability theory. This calculation model consists of heat transfer from the heat transfer medium to a tube, of heat transfer through a tube, of heat transfer through a rib and thermal decomposition on a rib by means of Bessel functions, of the calculation of the ribbed surface efficiency, of heat transfer from parallel plates and of heat transfer from a horizontal tube. As the floor convector performance depends on all the above mentioned heat transfers, a mathematical model of the convector was set up from individual sub-processes in Excel. The individual models were interconnected so that the whole calculation could iterate on condition that the heat transferred by forced convection from the heat transfer medium to a tube had to be delivered by the floor convector on the air side by means of natural convection and radiation.

The calculation has to contain boundary conditions such as temperature of the heat transfer medium, ambient temperature, and a diameter of a tube with molded ribs. The convector thermal performance changes with the change in the input parameters. Their influence on the thermal performance can be seen from the following dependences. Criterion equations for individual processes of heat transfer are to be found in [1], [2] and [3].

\section{Optimization of construction parameters of a passive floor convector}

As the performance of a floor convector depends on more construction parameters of the convector it is good to optimize them simultaneously. From these optimizations a 3-D Graph1 was set up. It illustrates the dependence on the spacing and height of a rib at the ambient temperature $20{ }^{\circ} \mathrm{C}$, at the temperature of the heat transfer medium $75 / 65^{\circ} \mathrm{C}$, pipe diameter $18 \mathrm{~mm}$ and at the rib thickness $0.25 \mathrm{~mm}$. This model served for finding the optimal rib spacing at various rib heights to achieve the highest possible thermal performance of the floor convector. From the graphs and calculations it can be seen that the optimal spacing of ribbing at the ambient temperature $20{ }^{\circ} \mathrm{C}$ and temperature of heat transfer medium $75 / 65^{\circ} \mathrm{C}$ is $5.5 \mathrm{~mm}$ at the rib height $60-100 \mathrm{~mm}$, although according to the analyses of boundary layers a greater spacing is ideal. The use of

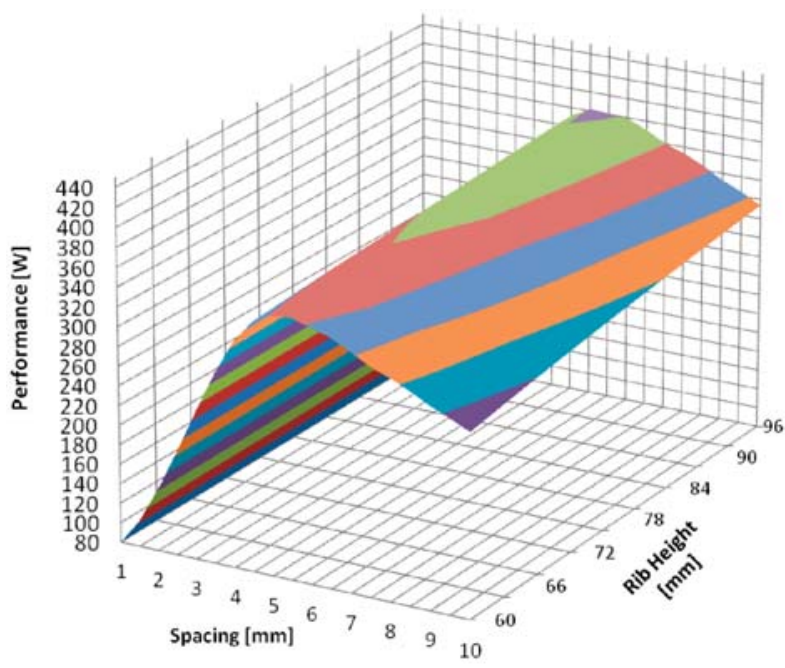

Graph 1 Performance of floor convector in dependence on rib spacing and height at the ambient temperature $20{ }^{\circ} \mathrm{C}$, temperature of heat transfer medium $75 / 65^{\circ} \mathrm{C}$, pipe diameter $18 \mathrm{~mm}$ and rib thickness $0.25 \mathrm{~mm}$

\section{Dependence of rib number on spacing}

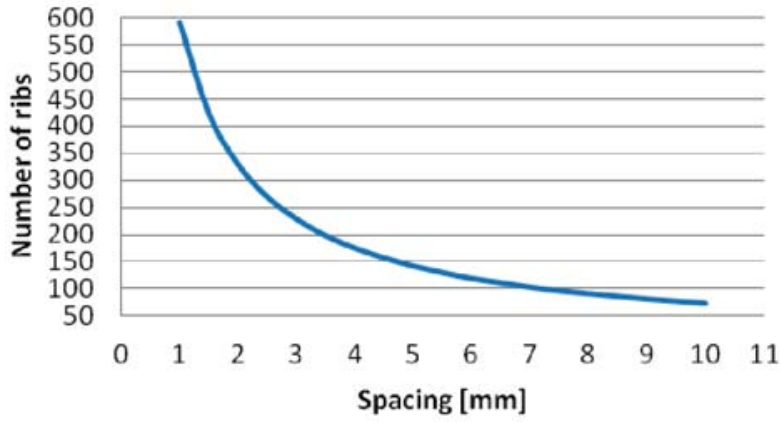

Graph 2 Dependence of rib number on spacing of ribbed surface at a ribbing length $740 \mathrm{~mm}$ 


\section{Rib thickness [mm]}
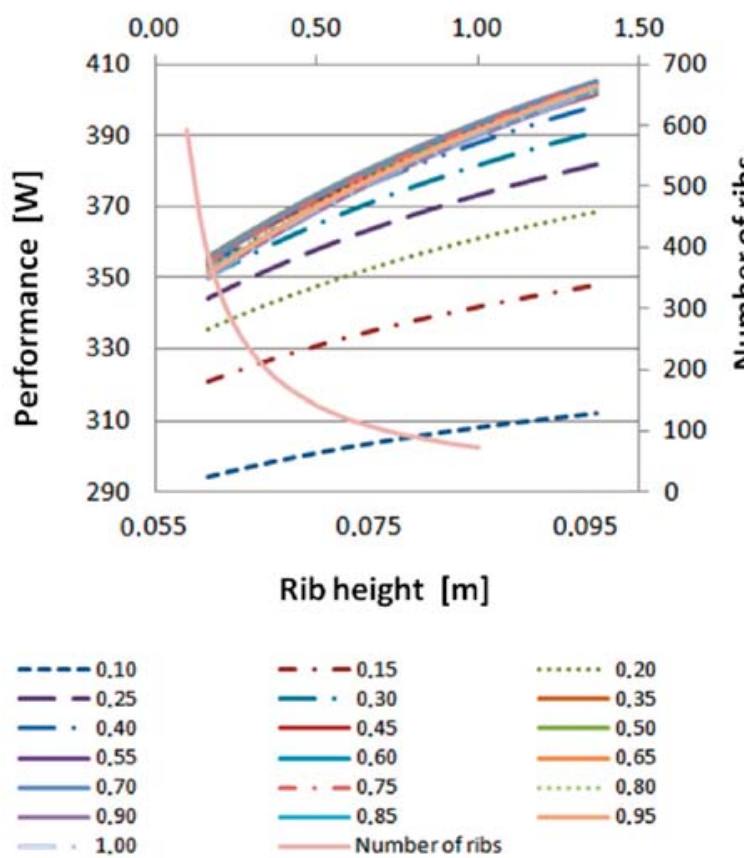

Graph 3 Performance of floor convector in dependence on rib thickness and height at the ambient temperature $20^{\circ} \mathrm{C}$, temperature of heat transfer medium $75 / 65^{\circ} \mathrm{C}$, pipe diameter $18 \mathrm{~mm}$ and at a rib spacing $5.5 \mathrm{~mm}$

greater spacing would result in reduction of heat transfer surface, thus leading to the reduction of the total thermal performance of the floor convector. On the Graph-2 we can see dependence of rib number on spacing of ribbed surface at ribbing length of floor convector $740 \mathrm{~mm}$.

For further increase in the thermal performance of the model floor convector with natural convection, another model was created. The knowledge gathered from previous optimization was used, namely the rib spacing $5.5 \mathrm{~mm}$, which showed to be the most suitable. In this model the dependence of thermal performance on the rib height $(60-100 \mathrm{~mm})$ and thickness (Graph3) was modeled. The influence of the rib height and thickness on the total performance of the floor convector can be seen in the graph. The floor convector performance grows with the increasing height of the rib, which is natural as the heat transfer surface also extends. An important finding though is a considerable influence of the rib thickness on the total thermal performance dissipated to the air by means of natural convection, which can be best observed in Graph4. In this graph it is possible to observe a considerable influence of the floor convector rib thickness on the total performance at individual heights of the rib (for better illustration only some performance curves of the model floor convector were chosen), where, for example, at the rib height $60 \mathrm{~mm}$ the ideal rib thickness is $0.55 \mathrm{~mm}$ (thermal performance $355.9 \mathrm{~W}$ ); at the rib height $80 \mathrm{~mm}$ the ideal thickness is $0.6 \mathrm{~mm}(387.52 \mathrm{~W})$ and at the rib height $96 \mathrm{~mm}$ it is as many as $0.65(405.4 \mathrm{~W})$. It is also obvious that further increase in the rib thickness does not result in the increase of performance due to following two reasons: when increasing the rib thickness within the same total length of the ribbed surface, the number of ribs decreases (reduction of heat transfer surface); even if the amount of heat supplied to the rib increases, which results in equalization of the rib temperature, we are unable to dissipate it into the surroundings by means of natural convection.

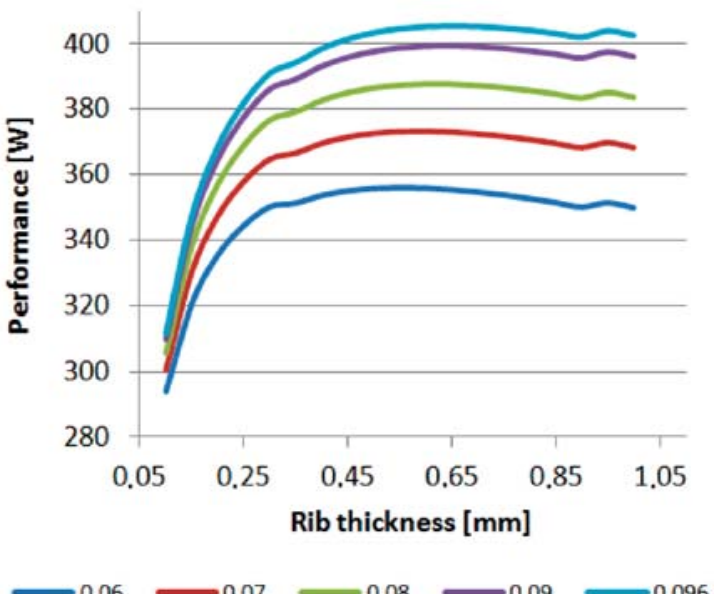

Graph 4 Floor convector performance in dependence on the rib thickness and height at ambient temperature $20{ }^{\circ} \mathrm{C}$, heat transfer medium temperature $75 / 65^{\circ} \mathrm{C}$, pipe diameter $22 \mathrm{~mm}$ and at a rib spacing $5.5 \mathrm{~mm}$

\section{Optimization of geometry of the floor convector housing}

Experimental measurement for optimization of the floor convector housing and its influence on the performance was made on a sample of the floor convector with the following construction parameters: length of ribbed surface $740 \mathrm{~mm}$, rib height $60 \mathrm{~mm}$, rib length $123 \mathrm{~mm}$, rib thickness $0.25 \mathrm{~mm}$, rib spacing $4 \mathrm{~mm}$ and pipe diameter $18 \mathrm{~mm}$. The temperature of heat transfer medium (temperature gradient) was $75 / 65^{\circ} \mathrm{C}$ and temperature of ambient air was $20^{\circ} \mathrm{C}$.

The floor convector was placed in the back part of the thermostatic chamber. An objective of this measurement was to find the most convenient slope of both the front and back sides of the floor convector housing on the performance itself.

First, we were changing the slope of the front side of the housing starting from $0^{\circ}$, when the front side of the housing was completely open, up to $90^{\circ}$, when it was completely closed. Gradually, the measurements were made for $0^{\circ}, 15^{\circ}, 30^{\circ}, 45^{\circ}, 60^{\circ}, 75^{\circ}$ and $90^{\circ}$ slope of the front side of the housing. From these optimizations 
Graph5 illustrating the dependence of the floor convector performance on the slope of the front side of the housing was set up. It can be seen from the graph that at a slope of $0^{\circ}$ (when the front side of the convector housing was completely open), the floor convector achieved the highest performance. The convector performance was the lowest at a slope of $90^{\circ}$ (the front side of the housing was completely closed).

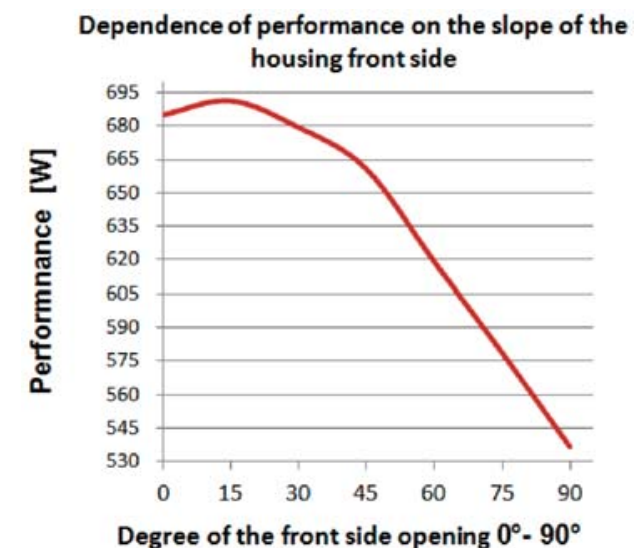

Graph 5 Dependence of the floor convector performance on the slope of the housing front side

Having completed the changes in the slope of the housing front side, we changed, in a similar way, the slope of the housing back side. It can be seen from Graph6 that similarly as in the case of the slope of the housing front side, the performance of the floor convector is the greatest at the complete opening $\left(0^{\circ}\right.$ slope of the housing) and the lowest at the complete closing $\left(90^{\circ}\right.$ slope of the housing). Graph7 illustrates the performance differences at the slope of the front and back sides of the floor convertor housing. The difference is due to the fact that at the opening of the back

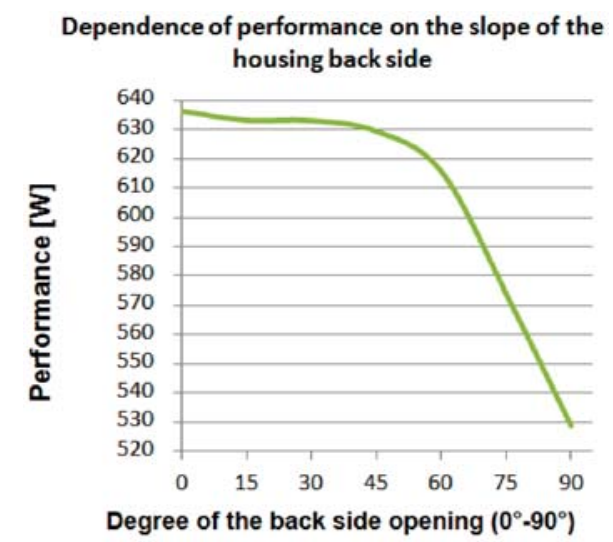

Graph 6 Dependence of the floor convector performance on the slope of the housing back side side of the housing the heat transferred to the space washes the back wall of the thermostatic chamber which is cold. Thus the warm air from the convector is mixed with the cold wall and swirls occur, which results in reduction of the thermal performance. The occurrence of whirls can be seen in Fig. 3, in which the floor convector model was created by means of CFD simulation in the program Ansys 12.0. Fig. 3 presents air flow trajectory with velocity contours where the occurrence of swirls can be seen in the wall area of the thermostatic chamber.

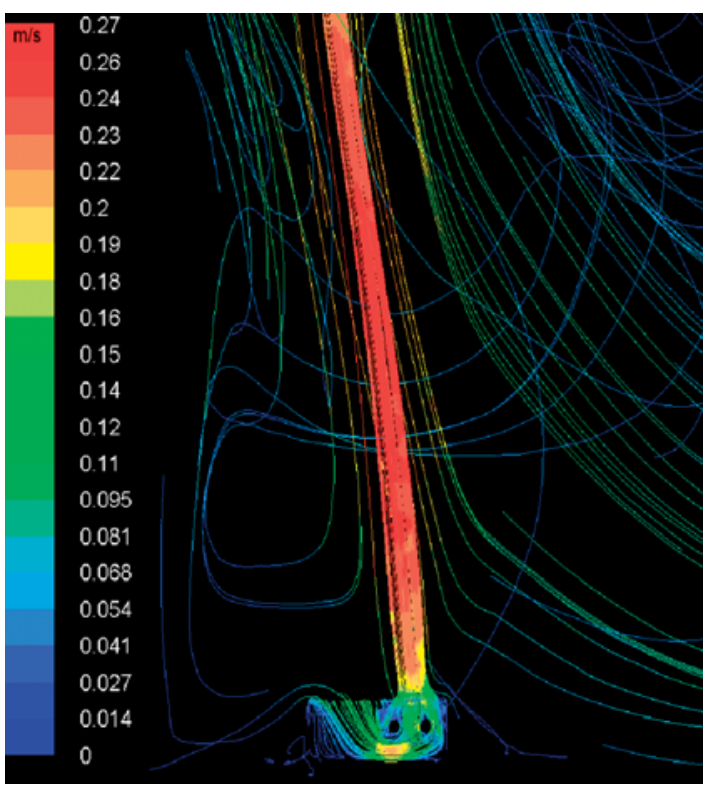

Fig. 3 Air flow trajectory with velocity contours

\section{Dependence of performance on the slope of the housing front and back sides}

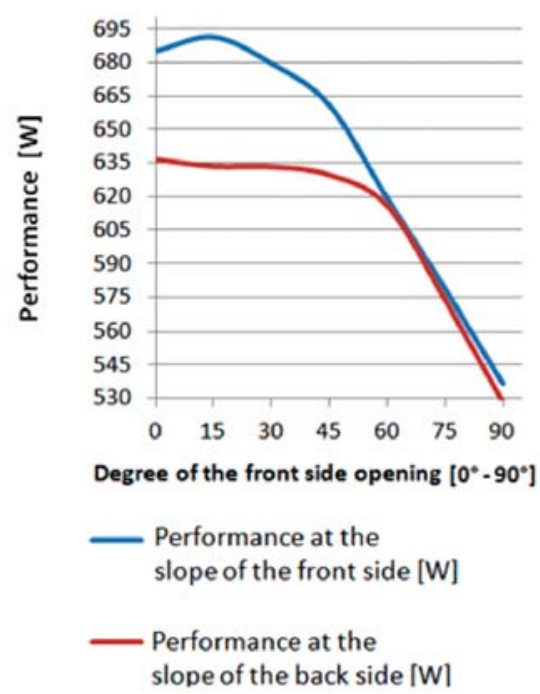

Graph 7 Comparison of the floor convector performance in dependence on the slope of front and back sides of the housing 
The last measurement we made dealt with the influence of the slope of both sides of the housing on the floor convector performance. The slope of the housing sides was changed simultaneously, again in the range from $0^{\circ}$ up to $90^{\circ}$. Graph 8 illustrates the dependence of the floor convector performance on the slope of both sides of the housing. From the graph it follows that similarly as in the previous cases, the floor convector performance is the highest

\section{Dependence of performance on the slope of both sides of the housing}

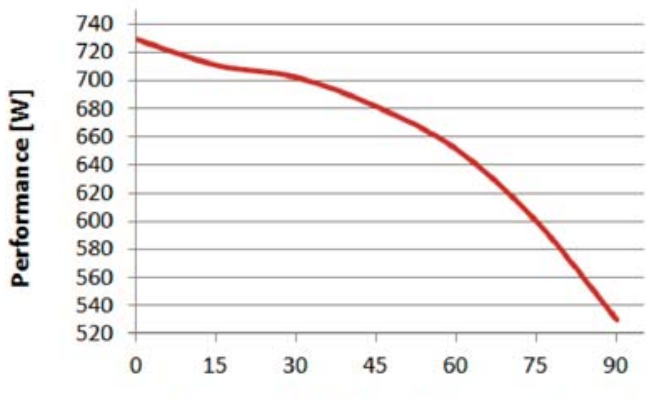

Degree of opening of both sides of the housing $\left(0^{\circ}-90^{\circ}\right)$

Graph 8 Floor convector performance in dependence of the slope of the housing both sides

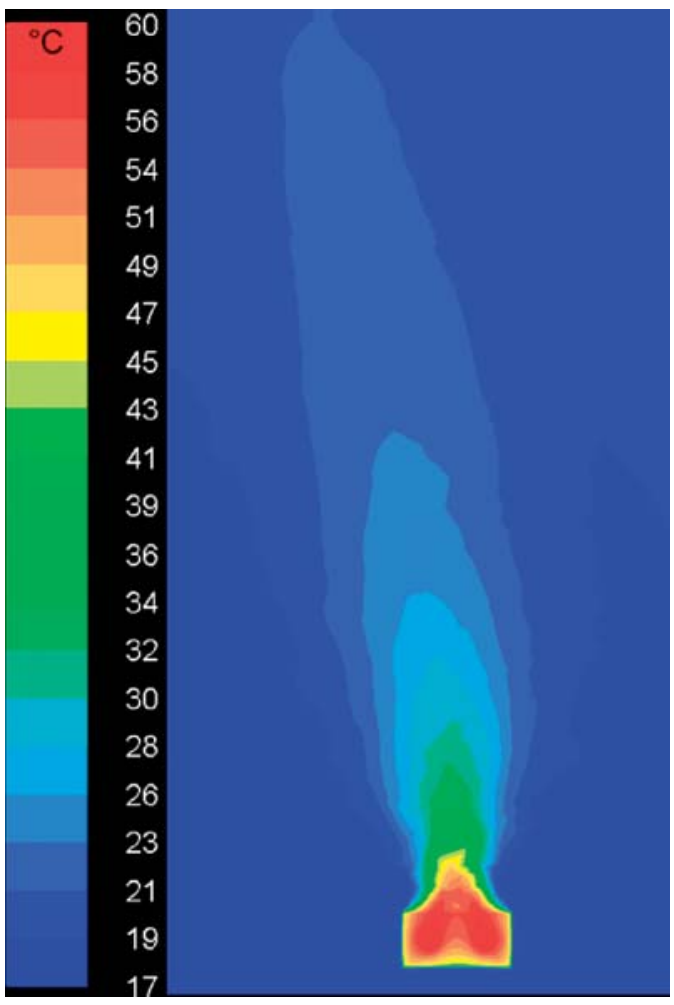

Fig 4 Visualization of thermal field from a sample of a floor convector without housing at the complete opening of the housing and the lowest at the complete closing of the housing. The influence of the housing on the heat spreading from the floor convector can be compared in Figs. 4 and 5 which present visualizations of thermal fields from the sample of the floor convector made by means of CFD simulations in program Ansys. Comparing the figures we can see a considerable influence of the housing on the flow of air to the surrounding areas [4], [5].

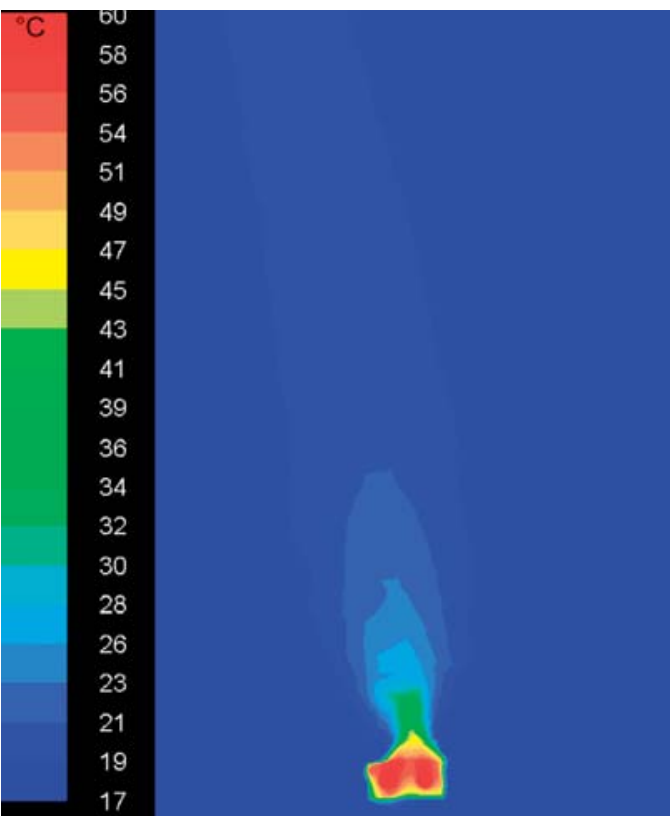

Fig. 5 Visualization of thermal field from a sample of a floor convector with housing

\section{Conclusion}

From the analysis of individual simulation calculations it can be seen that for the floor convector with natural convection having the ribbed surface length of $740 \mathrm{~mm}$, at temperature gradient $75 / 65^{\circ} \mathrm{C}$ and ambient temperature of $20^{\circ} \mathrm{C}$ with the tube diameter $18 \mathrm{~mm}$, with the rib length of $123 \mathrm{~mm}$ at the rib thickness $0.25 \mathrm{~mm}$ (the rib thickness used by a majority of floor convector manufacturers) is the optimal rib spacing $5.5 \mathrm{~mm}$, where at the rib height $60 \mathrm{~mm}$ it features the thermal performance $344.395 \mathrm{~W}$, at the height $80 \mathrm{~mm}$ it features the performance $368 \mathrm{~W}$ and at the rib height $96 \mathrm{~mm}$ its thermal performance is $382 \mathrm{~W}$. At further analyses and model creation in dependence of the rib height (60-100 $\mathrm{mm}$ ) and rib thickness a considerable influence of the rib thickness on the floor convector performance was observed. The performance of modeled floor convector at identical boundary conditions increases with the increasing rib thickness which caused the increase of thermal performance at the rib height of $60 \mathrm{~mm}$ up to $355.94 \mathrm{~W}$, at the height $80 \mathrm{~mm}$ up to $387.52 \mathrm{~W}$ and at the height $96 \mathrm{~mm}$ up to $405.44 \mathrm{~W}$ at the same lengths of ribbed surface as at the rib 
thickness of $0.25 \mathrm{~mm}$. It is also obvious that the performance of a floor convector is, to a certain degree, influenced by the housing geometry. At the complete opening of the front side of the housing the thermal performance achieved $648.88 \mathrm{~W}$, and at the complete closing the thermal performance value was $536.75 \mathrm{~W}$. The thermal performance at the complete opening of the back side of the housing achieved the value $636.38 \mathrm{~W}$ and at the complete closing of the back side it achieved the value $528.56 \mathrm{~W}$. At the change of slope of both sides of the housing the thermal performances achieved at the complete opening the value $729 \mathrm{~W}$ and at the complete closing it achieved the value $529.38 \mathrm{~W}$.

It deals with the optimization of geometric shapes of floor convectors at the lowest material and production costs with an objective to achieve their maximal performance parameters.

This paper was written within the project VEGA-1/1127/11

\section{References}

[1] KAPJOR, A.: Optimization of Construction Parameters of Passive Floor Convectors. Dissertation thesis. Zilina 2009

[2] REMSBURG, R.: Thermal Design of Electronic Equipment. Boca Raton : CRC Press LLC, 2001

[3] FRANK, P, INCOPERA, D., DEWIT, P. et al.: Fundamentals of Heat and Mass Transfer, John Wiley \& Sons

[4] DOBAKOVA, R., BRESTOVIC, T.: Calculation of Thermal Loss of Above-Ground and Underground Trenchless Pipe Laying by Means of Program VTSP. Strojarstvo, June 2008, pp. 18-19th Meeting of departments of fluid mechanics and thermomechanics, 2009. Demanovska dolina. ISSN 1335-2938.

[5] VITAZEK, I.: Thermal Technology and Waterworks - second unchanged edition. Nitra : SPU publishers, 2008, 104 p. 